\title{
Menopausal symptoms: Do life events predict severity of symptoms in peri- and post-menopause?
}

\author{
Filipa Pimenta*, Isabel Leal, João Maroco, Catarina Ramos \\ Psychology and Health Research Unit, ISPA - Instituto Universitário, Portugal
}

\section{A R T I C L E I N F O}

\section{Article history:}

Received 21 November 2011

Received in revised form 15 April 2012

Accepted 17 April 2012

\section{Keywords:}

Menopausal symptoms

Life events

Structural equation modeling

\begin{abstract}
A B S T R A C T
Objective: Hormonal changes during menopausal transition are linked to physical and psychological symptoms' emergence. This study aims to explore if life events predict menopausal symptoms.

Methods: This cross-sectional research encompasses a community sample of 992 women who answered to socio-demographic, health, menopause-related and lifestyle questionnaires; menopausal symptoms and life events were assessed with validated instruments. Structural equation modeling was used to build a causal model.

Results: Menopausal status predicted only three symptoms: skin/facial hair changes $(\beta=.136 ; p=.020)$, sexual $(\beta=.157 ; p=.004)$ and, marginally, vasomotor symptoms $(\beta=.094 ; p=.054)$. Life events predicted depressive $\operatorname{mood}(\beta=-.391 ; p=.002)$, anxiety $(\beta=-.271 ; p=.003)$, perceived cognitive impairment $(\beta=-.295 ; p=.003)$, body shape changes $(\beta=-.136 ; p=.031)$, aches/pain $(\beta=-.212 ; p=.007)$, skin/facial hair changes $(\beta=-.171 ; p=.021)$, numbness $(\beta=-.169 ; p=.015)$, perceived loss of control $(\beta=-.234$; $p=.008)$, mouth, nails and hair changes $(\beta=-.290 ; p=.004)$, vasomotor $(\beta=-.113 ; p=.044)$ and sexual symptoms $(\beta=-.208 ; p=.009)$.

Conclusions: Although women in peri- and post-menopausal manifested higher symptoms' severity than their pre-menopausal counterparts, only three of the menopausal symptoms assessed were predicted by menopausal status. Since the vast majority of menopausal symptoms' severity was significantly influenced by the way women perceived their recent life events, it is concluded that the symptomatology exacerbation, in peri- and post-menopausal women, might be due to life conditions and events, rather than hormonal changes (nonetheless, the inverse influence should be investigated in future studies). Therefore, these should be accounted for in menopause-related clinical and research settings.
\end{abstract}

(C) 2012 Elsevier Ireland Ltd. All rights reserved.

\section{Introduction}

The severity of menopausal symptoms, which have their highest prevalence in late peri-menopause and early post-menopause [1], is known to be influenced by bio-psycho-social factors [2-4].

The symptoms reported during climacteric period have been associated with the reduction of estrogens [5]. However, the symptoms' onset is also affected by well-being, professional status, smoking and education [6]; lifestyle can also entail an influence in psychological symptoms of menopause, namely depressive mood and anxiety [7].

During peri-menopause, several symptoms may arise and can prevail until post-menopause. Among others, the literature has documented hot flushes, joint pain, sleep disorder, depressive

\footnotetext{
* Corresponding author at: Psychology and Health Research Unit, ISPA - Instituto Universitário, Rua Jardim do Tabaco, 34, 1149-041 Lisboa, Portugal. Tel.: +351 218811700; fax: +351218860954

E-mail address: filipa_pimenta@ispa.pt (F. Pimenta).
}

mood, irritability, fatigue and libido decrease as the most common symptoms [8-12]. Other symptoms may arise during the menopausal transition, as hormone therapy's side effects; these include the increment of facial hair, weight gain, breast tenderness, hair loss, and changes in the skin (dryness or texture and tone alterations) [13].

Vasomotor and sexual symptoms are the ones that have been identified as the clinical manifestations more strongly associated with the menopausal status $[6,9,14,15]$. Other symptoms, such as psychological and somatic symptoms (other than sexual and vasomotor) related with the menopause process are more likely to be associated with psychosocial factors [15].

The literature on associations between life stressors and both psychological and physical symptoms has derived from the assumption that life changes are stressful and demand an adaptation by the individuals, and that the presence of recent stressful events might increase people's susceptibility to develop these symptoms [16,17]. However, life events cannot be assumed to promote distress per se; instead, it is sustained that the impairment is mediated by the stress evocated by a certain unwanted aspect of 
an experience, rather than by the change itself [18]. Therefore, it is pertinent to explore, not merely if the presence of certain events might predict the severity of psychological and physical symptoms, but rather if a certain degree of stress and desirability, attributed to a range of life experiences, may foster specific symptomatology.

Some studies have identified negative life events as a strong predictor of some menopausal symptoms $[2,14]$. The empty nest experience, everyday-life stress, health problems (partner's or own), death of a loved one, offspring's adolescence, financial difficulties, diseased parents, reformulation of family roles, professional changes, modifications in the interpersonal relationships and in the lifestyle are some of the experiences that midlife (and menopausal) women might face and which can be responsible for the exacerbation of some psychological symptoms during this period $[7,19,20]$.

A number of studies hypothesize that the manifestation of some menopausal symptoms might be due to the women's context and the way they perceive it, rather than to their menopausal status. Although there is evidence that the contextual variables (such as life events) might have an impact on the way women experience some of the menopausal symptoms, it is still unclear if this influence is exerted only by the way women perceived their context (specifically, the stress and desirability levels associated to major life events and daily hassles), regardless of other individual variables.

Since most studies do not control simultaneously the severity of menopausal symptoms and both personal variables (such as health and menopausal status, socio-demographic, among others) and contextual factors (namely, the impact - from extremely negative to extremely positive - that events have in menopausal women's lives), this study aims at developing a model which integrates both personal and contextual variables and assesses their predictive influence on menopausal symptoms. Thus, the specific aim of this study is to explore if menopausal symptoms (including a broad range of both physical and psychological clinical manifestations) are predicted by life events, controlling for confounding variables such as socio-demographic factors, health and menopause-related variables, and lifestyle, in a sample of peri- and post-menopausal women.

Additionally, it is also our objective to compare different menopausal statuses (namely, pre-, peri- and post-menopause) regarding the severity of menopausal symptoms, in a community sample.

\section{Methods}

\subsection{Participants}

A community sample of 992 women in pre-, peri and postmenopause was included in the present study. Table 1 describes the participants, aged between 42 and 60 years.

\subsection{Procedure}

This cross-sectional study encompasses a community sample which was recruited through community settings (such as schools, universities, and corporative settings), and also in the Gynecology consultation of a hospital, in the city of Lisbon. The vast majority of respondents who agreed to participate (that is, $89 \%$ ) were approached in an educational setting and were mothers and grandmothers of the students (only $7 \%$ of the respondents were recruited in the hospital, and $4 \%$ through enterprises).

Since the mean age for the occurrence of menopause has been identified as 51 years, participants were women with ages included in a range of nine years younger and nine years older than the mean menopause age. Hence, the inclusion criteria in this research were gender (female), literacy and age (between 42 and 60 years).

Women who fulfilled the inclusion criteria were directly contacted by the researcher herself or by a person of reference, who would explain the study based on the information contained in the informed consent form; the written informed consent, accompanied by the principal researcher's contacts and questionnaires were delivered in hand, inside an envelope. All the participants completed a paper version of all the questionnaires, and returned it to the researcher or person of reference in a sealed envelope.

The American Psychological Association's standards on the ethical treatment of participants were followed. A written informed consent form was delivered to all participants, explaining the aims of the study, emphasizing that the participation in this research was voluntary and that participants could interrupt their collaboration at any time, without any consequences.

After receiving the informed consent and agreeing to participate in the research, a sample of 1003 Portuguese women answered to all the instruments adequately ( 45 were excluded due to lack of sufficient information). In this study 992 participants were included since 11 women gave insufficient information to determine menopausal status.

\subsection{Measures}

\subsubsection{Menopause symptoms}

A validated version of the Menopause Symptoms' Severity Inventory, MSSI-38 [21] was used. This self-report inventory includes thirty-eight items, organized in twelve sets of menopausal symptoms (depressive mood; anxiety; perceived cognitive impairment; body shape changes; aches and pain; skin and facial hair changes; numbness; perceived loss of control; mouth, nails and hair changes; vasomotor, urinary and sexual symptoms). Both frequency and intensity of symptoms were measured in reference to the previous month, using a 5-point Likert-type scale which ranges from "never" (0) to "daily or almost every day" (4) and from "not intense" $(0)$ to "extreme intensity" (4), respectively. The severity of each symptom is calculated afterwards, using the mean between the values of frequency and intensity for each item. The development of MSSI-38 was supported by an extended literature review, pre-existing menopause-related instruments, and thirty-six semistructured interviews with peri- and post-menopausal women; the final version was reviewed by three consultants in women's health and menopause (two gynecologists and one health psychologist). This inventory has proven to have construct (that is, factorial, convergent and discriminant validity), criterion and external validity; moreover, a good reliability and sensitivity for all scales, has been shown $[21,22]$.

\subsubsection{Life events}

The Life Experiences Survey [16,23] evaluates the impact of a variety of events in the participants' life, during the previous month. This inventory includes 47 events (e.g. death of a close family member) that can be measured in a 7-point Likert-type scale, ranging from "very negative" $(-3)$ to "very positive" (3). There is also the possibility to answer "does not apply" for each event. Only events which were mentioned by at least $10 \%$ of the sample were included in the causal model. The instrument presented good psychometric properties in its Portuguese version [23].

\subsubsection{Menopausal and health-related variables}

The menopausal status was defined according to the Stages of Reproductive Aging Workshop's criteria [24]. Women in premenopause presented an absence of changes in their menstrual cycle. Peri-menopausal participants would report variable cycle 
Table 1

Distribution of the study's participants according to socio-demographic, health and menopause-related characteristics and lifestyle.

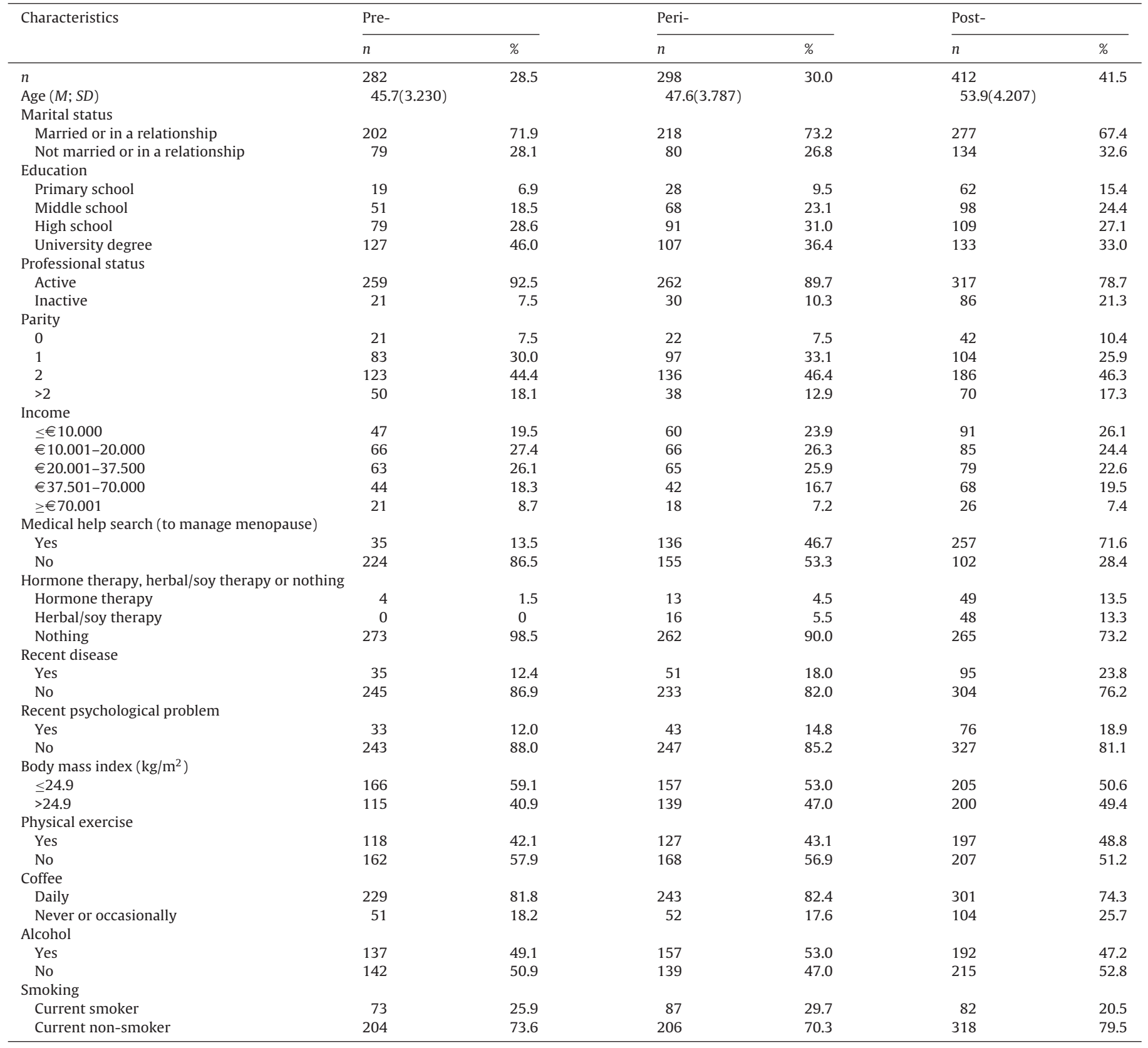

length (a difference of more than seven days, than usual) or had skipped two or more cycles and had an amenorrhea interval superior to sixty days. Post-menopausal women had at least a twelve-month period of amenorrhea.

Besides menopausal status, the use of hormone therapy, herbal/soy products or nothing to manage menopause symptoms was also asserted. In addition, search for medical help to manage these symptoms was also controlled.

Health status (both physical and psychological), as menopausal status, was self-reported. The presence of a recent disease and of a psychological problem was asked to the participants.

\subsubsection{Lifestyle}

Alcohol and coffee intake, smoking, physical exercise and body mass index (BMI) were assessed.
Lifestyle habits were explored in terms of presence/absence, amount and/or frequency. Hence, physical exercise was measured in terms of times per week, and during how many minutes, the participant exercised; a mean value of weekly frequency and duration was used in the multivariated model. Coffee intake, when present, was assessed in a four-option scale, ranging from "occasionally" to "more than five per day". Alcohol intake, when observed, was measured both in terms of frequency ("daily", "every weekend" or "rarely") and quantity ("until I feel drunk", "moderately" or "less than a glass per occasion"); a mean value of both translates the alcohol consumption variable, in the causal model. Finally, for current smokers, smoking was quantified in a 6-point Likert-type scale that ranged from "less than 10 cigarettes per month", until "more than 40 cigarettes per day"; this quantification integrated the structural equation model to assert the influence of smoking on the menopausal symptoms' severity. 


\subsubsection{Socio-demographic characteristics}

Socio-demographic factors such as age, marital status, parity, professional status, educational level and family annual income were explored.

\subsection{Statistical analysis}

Missing values were imputated for variables, where its frequency was lower than $10 \%$ of the sample. This was done using the mean interpolation method.

The distribution of the variables studied was explored with SPSS Statistics (v. 19, IBM SPSS Inc., Chicago, IL).

To explore if there were significant differences regarding the severity of menopausal symptoms, the participants in the three menopausal stages (pre-, peri- and post-menopausal) were compared with a one-way ANOVA, followed by a Tukey's test, to identify if differences were observed between menopausal statuses.

Multicollinearity between the independent variables was explored with the variance inflation factor (VIF) given by SPSS Statistics (v. 19, IBM SPSS Inc., Chicago, IL). All variables presented a value below 5 , indicating the absence of collinearity [25].

To test the causal model for menopausal symptoms in periand post-menopausal participants, a structural equation model was built, relating the dependent variables (twelve sets of symptoms) with the eighteen independent variables (namely, age, parity, marital and professional status, income, education, presence of a recent psychological problem or a disease, transition from peri- to post-menopause, use of hormone therapy or herbal/soy products to manage menopause symptomatology, medical help search to deal with menopause, alcohol and coffee intake, smoking, physical exercise, body mass index and life events). A single multivariate structural model was built, including simultaneously all dependent and independent variables; the possible associations between independent (and also among dependent) variables was also controlled through the establishment of covariations.

The model was evaluated with SPSS AMOS software (v. 18, IBM SPSS Inc., Chicago, IL). The quality of the fit of the structural model was given by chi-square statistics $\left(\chi^{2} / d f\right)$, comparative fit index (CFI), goodness of fit index (GFI) and root mean square error of approximation (RMSEA), and the reference values currently practiced in structural equation modeling [26] were used. A two-step approach was employed to evaluate the causal structural model. First, the factor's measurement model was evaluated to demonstrate an acceptable fit. Thereafter, the structural causal model, encompassing the dependent and independent variables, was adjusted and the significance of the causal trajectories was evaluated.

\section{Results}

Women in the three different menopausal statuses were compared regarding the twelve sets of menopausal symptoms. Mean scores (which can range from 0 to 4 ) and standard deviations, of each symptom in each menopausal status, are also given. The results are shown in Table 2.

To assert if life events could be a significant predictor of menopausal symptoms, in a sample of peri- and post-menopausal women (with a total dimension of 710 participants), a single multivariate causal model encompassing simultaneously the eighteen independent variables (age, parity, marital and professional status, household income, education, presence of a recent psychological problem or a disease, transition from peri- to post-menopause, use of hormone therapy or herbal/soy products to manage menopause symptomatology, medical help search do deal with menopause, alcohol and coffee intake, smoking, physical exercise, body mass index and life events) was built.

Both the measurement $\left(\chi^{2} / d f=2.153 ; C F I=.871 ; G F I=.852\right.$; $R M S E A=.041 ; p=1.000 ;$ C.I. $90 \%=] .039 ; .042[)$ and the structural model $\left(\chi^{2} / d f=1.967 ; C F I=.860 ; G F I=.848 ; R M S E A=.037 ; p=1.000\right.$; C.I. $90 \%=] .036 ; .039[$ ) evidenced a good fit. The structural model explored is represented in Fig. 1.

As shown in Fig. 1, the variability of the menopausal symptoms perceived severity, accounted by this causal model, ranges from $15 \%$ (in the case of skin and facial hair changes) to $34 \%$ (depressive mood).

Given the high number of trajectories, only significant ones are presented in Table 3.

\section{Discussion}

The literature presents contradictory findings regarding symptoms' exacerbation and menopausal status. Menopausal symptoms are expected to be exacerbated in peri-menopause and to decrease in post-menopause [2], and the only symptoms that post-menopausal women seem to have more exacerbated than peri-menopausal women are vasomotor ones [3]. However, it has also been observed that women in post-menopause present higher rates of menopausal symptoms than their counterparts in peri-menopause [27]. Our results support the latter conclusion, since post-menopausal women presented higher mean scores for all symptoms, although only aches and pain, vasomotor, sexual and urinary symptoms, and skin and facial hair changes were significantly higher in post-menopause (compared with their perimenopause counterparts).

The literature has also highlighted that psychological symptoms are frequent in pre-menopausal women and associated with vasomotor symptoms [3]. Nonetheless, peri-menopause has also been identified in another study as the menopausal stage were psychological symptoms are more prevalent [15]. In this research, all symptoms, both psychological and somatic, were significantly elevated in peri- and post-menopausal women when compared with their pre-menopausal counterparts; the only exception was skin and facial hair changes, and urinary symptoms that did not vary significantly between participants in pre-menopause and in the menopausal transition. Still concerning psychological symptoms, when compared with post-menopausal participants, women in peri-menopause did not differ significantly, specifically in terms of perceived loss of control, anxiety and depressive mood's severity.

Moreover, the severity of menopausal symptoms in this community sample was low: in a scale ranging from 0 to 4 , the symptoms varied between a mean score of $.215(S D=.432$; perceived loss of control in pre-menopausal participants) and 1.399 $(S D=.926$; anxiety in post-menopausal).

In this study, higher education and income were significant predictors of lower severity of menopausal symptoms. These two characteristics have been emphasized, in the past, as influencing the way women experience symptoms and manage the search for medical care: women with higher socio-economic status and more schooling have more access to health care systems and use more often hormone therapy for menopausal symptoms [9]. In addition, it can be hypothesized that these factors provide, to midlife women, not only more medical help, but also more support mechanisms and strategies, which may allow them to manage their menopausal symptoms (and their lives) differently than their counterparts with lower educational level and economical status. This might partially explain how women with more schooling years and a higher household income presented a lower severity of depressive mood, aches and pain, changes related with the mouth, nails and hair, sexual symptoms, numbness and perceived loss of control. 
Table 2

Menopausal symptoms: comparison between pre-, peri and post-menopausal participants.

\begin{tabular}{|c|c|c|c|c|c|c|}
\hline \multirow[t]{2}{*}{ Menopausal symptoms } & \multirow[t]{2}{*}{ Pre- $(n=282) M(S D)$} & \multirow[t]{2}{*}{ Peri- $(n=298) M(S D)$} & \multirow[t]{2}{*}{ Post- $(n=412) M(S D)$} & \multicolumn{3}{|c|}{ ANOVA one-way } \\
\hline & & & & & & $M D(S E) p$ \\
\hline Depressive mood & $.771(.894)$ & $.958(.909)$ & $1.032(.952)$ & $\begin{array}{l}\text { Pre- } \\
\text { Pre- } \\
\text { Peri- }\end{array}$ & $\begin{array}{l}\text { Peri- } \\
\text { Post- } \\
\text { Post- }\end{array}$ & $\begin{array}{l}-.187(.077) .042 \\
-.262(.073) .001 \\
-.075(.072) .551\end{array}$ \\
\hline Perceived cognitive impairment & $.832(.833)$ & $1.129(.952)$ & $1.230(.962)$ & $\begin{array}{l}\text { Pre- } \\
\text { Pre- } \\
\text { Peri- }\end{array}$ & $\begin{array}{l}\text { Peri- } \\
\text { Post- } \\
\text { Post- }\end{array}$ & $\begin{array}{l}-.297(.078)^{* * *} \\
-.397(.073)^{* * *} \\
-.101(.072) .340\end{array}$ \\
\hline Aches and pain & $.966(.818)$ & $1.227(.873)$ & $1.396(.934)$ & $\begin{array}{l}\text { Pre- } \\
\text { Pre- } \\
\text { Peri- }\end{array}$ & $\begin{array}{l}\text { Peri- } \\
\text { Post- } \\
\text { Post- }\end{array}$ & $\begin{array}{l}-.262(.074) .001 \\
-.430(.069)^{* * *} \\
-.168(.068) .037\end{array}$ \\
\hline Vasomotor symptoms & $.263(.534)$ & $.730(.979)$ & $1.102(1.186)$ & $\begin{array}{l}\text { Pre- } \\
\text { Pre- } \\
\text { Peri- }\end{array}$ & $\begin{array}{l}\text { Peri- } \\
\text { Post- } \\
\text { Post- }\end{array}$ & $\begin{array}{l}-.467(.083)^{* * *} \\
-.839(.077)^{* * *} \\
-.373(.076)^{* * *}\end{array}$ \\
\hline Numbness & $.574(.881)$ & $.791(1.012)$ & $.954(1.058)$ & $\begin{array}{l}\text { Pre- } \\
\text { Pre- } \\
\text { Peri- }\end{array}$ & $\begin{array}{l}\text { Peri- } \\
\text { Post- } \\
\text { Post- }\end{array}$ & $\begin{array}{l}-.217(.084) .028 \\
-.380(.079)^{* * *} \\
-.163(.078) .092\end{array}$ \\
\hline Mouth, nails and hair changes & $.461(.660)$ & $.647(.846)$ & $.710(.833)$ & $\begin{array}{l}\text { Pre- } \\
\text { Pre- } \\
\text { Peri- }\end{array}$ & $\begin{array}{l}\text { Peri- } \\
\text { Post- } \\
\text { Post- }\end{array}$ & $\begin{array}{l}-.186(.068) .016 \\
-.249(.063)^{* * *} \\
-.063(.062) .575\end{array}$ \\
\hline Anxiety & $1.095(.842)$ & $1.379(.895)$ & $1.399(.926)$ & $\begin{array}{l}\text { Pre- } \\
\text { Pre- } \\
\text { Peri- }\end{array}$ & $\begin{array}{l}\text { Peri- } \\
\text { Post- } \\
\text { Post- }\end{array}$ & $\begin{array}{l}-.284(.075)^{* * *} \\
-.304(.070)^{* * *} \\
-.020(.069) .954\end{array}$ \\
\hline Skin and facial hair changes & $.364(.699)$ & $.452(.758)$ & $.666(.831)$ & $\begin{array}{l}\text { Pre- } \\
\text { Pre- } \\
\text { Peri- }\end{array}$ & $\begin{array}{l}\text { Peri- } \\
\text { Post- } \\
\text { Post- }\end{array}$ & $\begin{array}{l}-.087(.066) .380 \\
-.302(.062)^{* * *} \\
-.214(.061) .001\end{array}$ \\
\hline Urinary symptoms & $.513(.751)$ & $.626(.876)$ & $.857(1.021)$ & $\begin{array}{l}\text { Pre- } \\
\text { Pre- } \\
\text { Peri- }\end{array}$ & $\begin{array}{l}\text { Peri- } \\
\text { Post- } \\
\text { Post- }\end{array}$ & $\begin{array}{l}-.114(.077) .302 \\
-.345(.072)^{* * *} \\
-.231(.071) .003\end{array}$ \\
\hline Sexual symptoms & $.528(.794)$ & $.892(1.018)$ & $1.380(1.208)$ & $\begin{array}{l}\text { Pre- } \\
\text { Pre- } \\
\text { Peri- }\end{array}$ & $\begin{array}{l}\text { Peri- } \\
\text { Post- } \\
\text { Post- }\end{array}$ & $\begin{array}{l}-.364(.089)^{* * *} \\
-.853(.083)^{* * *} \\
-.488(.082)^{* * *}\end{array}$ \\
\hline Body shape changes & $.789(.874)$ & $1.118(1.042)$ & $1.135(1.094)$ & $\begin{array}{l}\text { Pre- } \\
\text { Pre- } \\
\text { Peri- }\end{array}$ & $\begin{array}{l}\text { Peri- } \\
\text { Post- } \\
\text { Post- }\end{array}$ & $\begin{array}{l}-.330(.086)^{* * *} \\
-.346(.081)^{* * *} \\
-.016(.080) .977\end{array}$ \\
\hline Perceived loss of control & $.215(.432)$ & $.364(.624)$ & $.450(.695)$ & $\begin{array}{l}\text { Pre- } \\
\text { Pre- } \\
\text { Peri- }\end{array}$ & $\begin{array}{l}\text { Peri- } \\
\text { Post- } \\
\text { Post- }\end{array}$ & $\begin{array}{l}-.149(.051) .011 \\
-.236(.048)^{* * *} \\
-.087(.047) .160\end{array}$ \\
\hline
\end{tabular}

$M D=$ mean difference; $S E=$ standard error.

Bold values highlight the statistically significant $p$-values (i.e. $p<.05$ ).

${ }^{* * *} p<.001$.

Marital status has been previously identified as a predictor of sexual symptoms during the menopausal transition $[28,29]$. The results of the present study emphasized this: married women (or with a partner) had more severe sexual symptoms than their counterparts who were not married or in a relationship. Although it was not controlled, frequency of sexual activity could contribute to the understanding of this particular result. Besides sexual difficulties, marital status as well as parity, were significantly linked to vasomotor symptoms; hence, women with more children and who were not married (or in a relationship) reported less severe vasomotor symptoms.

The health status, both physical and psychological, can be also significantly related with the symptomatology occurring during the menopause process, namely with sexual symptoms [28]. In this study, besides sexual symptoms, self-reported physical and psychological status significantly predicted the vast majority of menopausal symptoms.

The peri-menopausal status has been identified as a risk factor for somatic and vasomotor symptoms [2]. The transition from peri- to post-menopause was significantly associated with sexual and skin and facial hair changes (vasomotor symptoms were predicted by menopausal status but only in a marginally significant way), in the present study. This emphasizes the conclusions drawn elsewhere: hypoestrogenism subsequent to menopause can lead to changes in the skin [30] and there is a significant connection between the menopausal stage and sexual symptoms [15].

Furthermore, the search for medical help to manage menopause, significantly predicted both physical and psychological symptoms: women who had used health care for menopause management presented higher severity of symptoms independently of socio-demographic, lifestyle, health and menopausal status and life events. Previous results have demonstrated that there is an association between seeking for medical help and the frequency of menopausal symptoms, which was influenced by socio-demographic characteristics [9].

The use of herbal/soy products to manage menopausal symptoms was significantly associated with more severe vasomotor and sexual symptoms, as well as body shape modifications. Therefore, this result regarding the use of these natural products might translate an insufficient clinical control and a mismatching between personal needs of the symptomatic women and products' use. In addition, it has been evidenced that herbal therapies for menopausal symptoms might be ineffective [31,32], and some might not meet the necessary safety conditions [33]. 


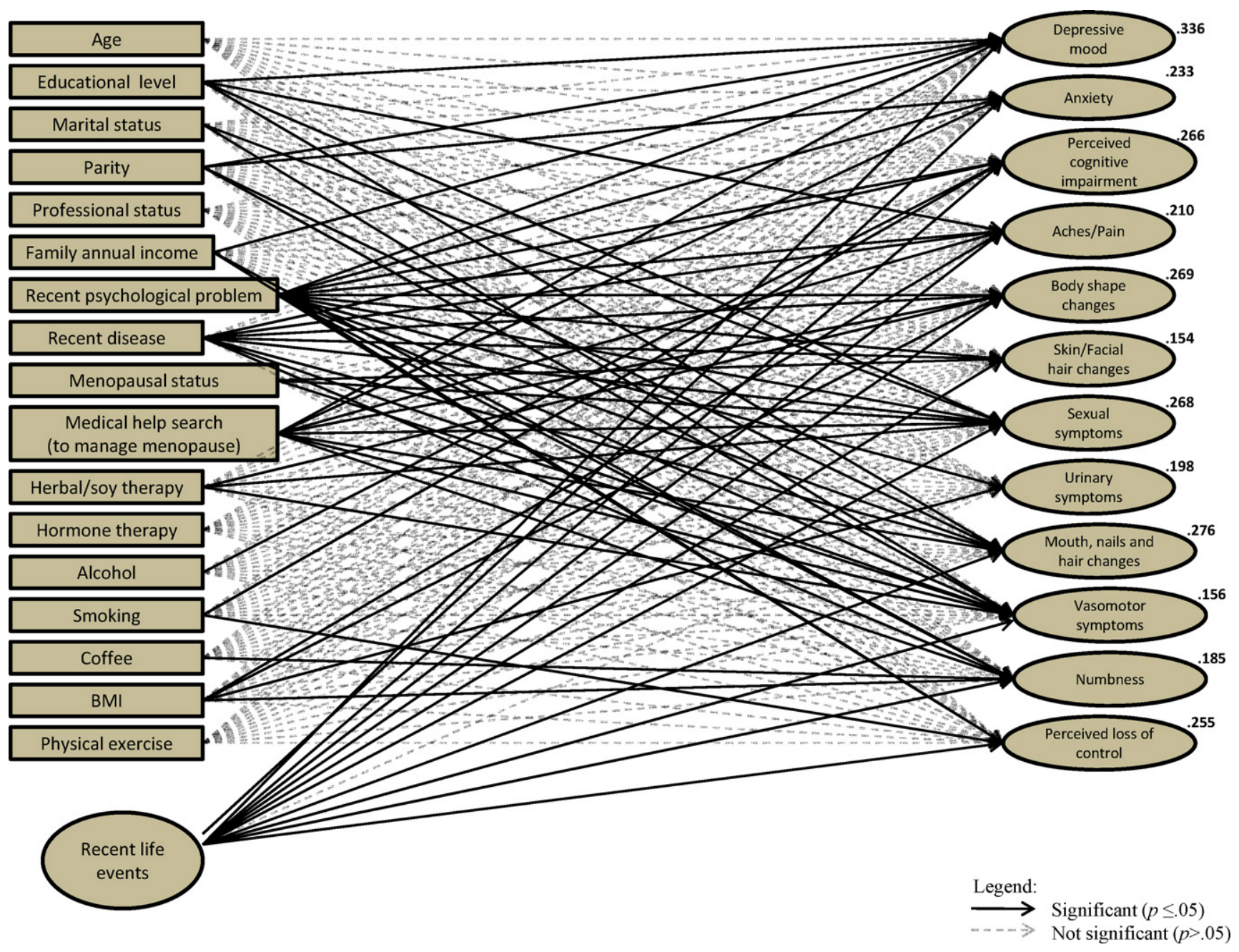

Fig. 1. Causal model for menopausal symptoms' severity: its relation with socio-demographics, health and menopause-related variables, lifestyle and recent life events.

Further research on the impact of herbal/soy therapies is necessary to confirm them as an eligible treatment of menopause-related symptomatology. However, it is also reasonable to think that women without symptoms are less likely to use herbal/soy products. In addition, it can be hypothesized that some women with bothersome symptoms may have opted or have been suggested to use natural products, in alternative to the hormonal therapy.

And, although the previously analyzed causal relationships have proven to be significant, the reverse influence direction (i.e. the influence symptoms' severity might have on the search for medical help and the use of herbal supplements) should also be analyzed in future studies.

A higher BMI was also a significant predictor for several physical symptoms; hence women with a more elevated body weight would present more severe complaints in terms of aches and pain, numbness, urinary symptoms and body shape changes. It has been evidenced elsewhere that the menopausal status does not have an impact in self-rated health; however, modifications in BMI can predict a change in the perceived health status [34]. This data is relevant as an increase in weight can be reported around the menopause transition [35], and weight gain prevention should be targeted in order to prevent its impact not only in the body shape perception, but also in the perceived health status and specific physical symptoms that are, as demonstrated by our results, worsened with higher body weight.
Smoking seems to be associated to less severe self-reported cognitive impairment and perceived loss of control since it is a significant and negative predictor. Prior outcomes have identified a moderate alcohol intake (when accompanied with physical exercise and absence of smoking behavior) as beneficial to menopausal women's well-being [36]. Although perceived loss of control is treated as a dependent variable in the present study, it would be pertinent to explore, in future researches, if subjective loss of control is a significant mediator of menopausal symptoms' severity.

In this research, alcohol intake positively predicted perceived cognitive difficulties: participants who drank more alcohol manifested more severe perceived cognitive impairment than those who drank less (or no) alcohol.

A decline in the sexual life during the menopausal transition and post-menopause has been associated with a stressful life [29]. In addition, in a previous study, everyday stressful experiences had a negative impact in middle-aged women [36] and negative life events were presented as a risk factor for menopausal symptoms [2]. Specifically, negative events perceived as having an important impact in women's lives (as well as family dysfunction) incremented the risk for psychological symptoms: depression, anxiety and stress [3]. However, menopausal women might attribute certain symptoms (namely, a worsening in the sexual response) not only to life events, but also to physical and emotional changes subsequent to menopause [37]. 
Table 3

Significant structural weights: causal model relating the independent variables (socio-demographic, health and menopause-related factors, lifestyle and life events) with the dependent variable (menopausal symptoms).

\begin{tabular}{|c|c|}
\hline Significant trajectories & $\beta(S E) p$ \\
\hline Vasomotor symptoms $\leftarrow$ marital status & $.088(.059) .029$ \\
\hline Vasomotor symptoms $\leftarrow$ parity & $-.089(.027) .020$ \\
\hline Vasomotor symptoms $\leftarrow$ recent disease & $.122(.065) .002$ \\
\hline $\begin{array}{l}\text { Vasomotor symptoms } \leftarrow \text { recent psychological } \\
\text { problem }\end{array}$ & $.084(.070) .031$ \\
\hline Vasomotor symptoms $\leftarrow$ menopausal status & $.094(.066) .054$ \\
\hline $\begin{array}{l}\text { Vasomotor symptoms } \leftarrow \text { medical help search } \\
\quad \text { (to manage menopause) }\end{array}$ & $.175(.056)^{* * *}$ \\
\hline Vasomotor symptoms $\leftarrow$ herbal/soy products & $.131(.091)^{* * *}$ \\
\hline Vasomotor symptoms $\leftarrow$ life events & $-.113(.216) .044$ \\
\hline Sexual symptoms $\leftarrow$ marital status & $.160(.087)^{* * *}$ \\
\hline Sexual symptoms $\leftarrow$ educational level & $-.123(.027) .021$ \\
\hline Sexual symptoms $\leftarrow$ recent disease & $.109(.095) .011$ \\
\hline $\begin{array}{l}\text { Sexual symptoms } \leftarrow \text { recent psychological } \\
\text { problem }\end{array}$ & $.196(.104)^{* * *}$ \\
\hline Sexual symptoms $\leftarrow$ menopausal status & $.157(.098) .004$ \\
\hline $\begin{array}{l}\text { Sexual symptoms } \leftarrow \text { medical help search (to } \\
\text { manage menopause) }\end{array}$ & $.111(.082) .012$ \\
\hline Sexual symptoms $\leftarrow$ herbal/soy products & $.114(.133) .008$ \\
\hline Sexual symptoms $\leftarrow$ life events & $-.208(.410) .009$ \\
\hline Depressive mood $\leftarrow$ educational level & $-.116(.020) .010$ \\
\hline Depressive mood $\leftarrow$ household annual income & $-.101(.030) .019$ \\
\hline Depressive mood $\leftarrow$ parity & $.075(.029) .035$ \\
\hline $\begin{array}{l}\text { Depressive mood } \leftarrow \text { recent psychological } \\
\text { problem }\end{array}$ & $.284(.081)^{* * *}$ \\
\hline $\begin{array}{l}\text { Depressive mood } \leftarrow \text { medical help search (to } \\
\text { manage menopause) }\end{array}$ & $.074(.061) .046$ \\
\hline Depressive mood $\leftarrow$ life events & $-.391(.578) .002$ \\
\hline Aches and pain $\leftarrow$ educational level & $-.099(.024) .041$ \\
\hline Aches and pain $\leftarrow$ recent disease & $.109(.084) .005$ \\
\hline $\begin{array}{l}\text { Aches and pain } \leftarrow \text { recent psychological } \\
\text { problem }\end{array}$ & $.172(.093)^{* * *}$ \\
\hline $\begin{array}{l}\text { Aches and pain } \leftarrow \text { medical help search (to } \\
\text { manage menopause) }\end{array}$ & $.146(.073)^{* * *}$ \\
\hline Aches and pain $\leftarrow$ BMI & $.109(.008) .008$ \\
\hline Aches and pain $\leftarrow$ life events & $-.212(.394) .007$ \\
\hline $\begin{array}{l}\text { Mouth, nails and hair changes } \leftarrow \text { educational } \\
\text { level }\end{array}$ & $-.116(.022) .032$ \\
\hline Mouth, nails and hair changes $\leftarrow$ parity & $.147(.031)^{* * *}$ \\
\hline Mouth, nails and hair changes $\leftarrow$ recent disease & $.217(.076)^{* * *}$ \\
\hline $\begin{array}{l}\text { Mouth, nails and hair changes } \leftarrow \text { recent } \\
\text { psychological problem }\end{array}$ & $.175(.083)^{* * *}$ \\
\hline $\begin{array}{l}\text { Mouth, nails and hair changes } \leftarrow \text { medical help } \\
\text { search (to manage menopause) }\end{array}$ & $.140(.065) .002$ \\
\hline Mouth, nails and hair changes $\leftarrow$ life events & $-.290(.408) .004$ \\
\hline $\begin{array}{l}\text { Perceived loss of control } \leftarrow \text { household annual } \\
\text { income }\end{array}$ & $-.147(.023) .007$ \\
\hline $\begin{array}{l}\text { Perceived loss of control } \leftarrow \text { recent } \\
\text { psychological problem }\end{array}$ & $.281(.061)^{* * *}$ \\
\hline Perceived loss of control $\leftarrow$ smoking & $-.105(.014) .026$ \\
\hline Perceived loss of control $\leftarrow$ life events & $-.234(.244) .008$ \\
\hline Numbness $\leftarrow$ household annual income & $-.126(.036) .010$ \\
\hline Numbness $\leftarrow$ recent disease & $.112(.084) .006$ \\
\hline Numbness $\leftarrow$ recent psychological problem & $.095(.092) .020$ \\
\hline $\begin{array}{l}\text { Numbness } \leftarrow \text { medical help search (to manage } \\
\text { menopause) }\end{array}$ & $.110(.073) .009$ \\
\hline Numbness $\leftarrow$ BMI & $.124(.008) .004$ \\
\hline Numbness $\leftarrow$ coffee & $.095(.039) .022$ \\
\hline Numbness $\leftarrow$ life events & $-.169(.333) .015$ \\
\hline Anxiety $\leftarrow$ parity & $.083(.034) .023$ \\
\hline Anxiety $\leftarrow$ recent psychological problem & $.273(.091)^{* * *}$ \\
\hline $\begin{array}{l}\text { Anxiety } \leftarrow \text { medical help search (to manage } \\
\text { menopause) }\end{array}$ & $.121(.071) .002$ \\
\hline Anxiety $\leftarrow$ life events & $-.271(.478) .003$ \\
\hline $\begin{array}{l}\text { Perceived cognitive impairment } \leftarrow \text { recent } \\
\text { disease }\end{array}$ & $.116(.081) .003$ \\
\hline $\begin{array}{l}\text { Perceived cognitive impairment } \leftarrow \text { recent } \\
\text { psychological problem }\end{array}$ & $.273(.090)^{* * *}$ \\
\hline Perceived cognitive impairment $\leftarrow$ smoking & $-.094(.021) .023$ \\
\hline Perceived cognitive impairment $\leftarrow$ alcohol & $.092(.043) .021$ \\
\hline Perceived cognitive impairment $\leftarrow$ life events & $-.295(.479) .003$ \\
\hline Skin and facial hair changes $\leftarrow$ recent disease & $.100(.080) .032$ \\
\hline
\end{tabular}

Table 3 (Continued)

\begin{tabular}{lc}
\hline Significant trajectories & $\beta(S E) p$ \\
\hline $\begin{array}{l}\text { Skin and facial hair changes } \leftarrow \text { recent } \\
\quad \text { psychological problem }\end{array}$ & $.197(.088)^{* * *}$ \\
$\quad$ Skin and facial hair changes $\leftarrow$ menopausal & $.136(.083) .020$ \\
$\quad$ status & \\
Skin and facial hair changes $\leftarrow$ life events & $-.171(.297) .021$ \\
Body shape changes $\leftarrow$ medical help search (to & $.145(.072)^{* * *}$ \\
$\quad$ manage menopause) & $.165(.092)^{* * *}$ \\
Body shape changes $\leftarrow$ recent psychological & \\
$\quad$ problem & $.095(.083) .023$ \\
Body shape changes $\leftarrow$ recent disease & $.107(.117) .010$ \\
Body shape changes $\leftarrow$ herbal/soy products & $.388(.009)^{* * *}$ \\
Body shape changes $\leftarrow$ BMI & $-.136(.294) .031$ \\
Body shape changes $\leftarrow$ life events & $.241(.101)^{* * *}$ \\
Urinary symptoms $\leftarrow$ recent psychological & \\
$\quad$ problem & $.259(.009)^{* * *}$ \\
Urinary symptoms $\leftarrow$ BMI &
\end{tabular}

$\beta=$ standardized estimates SE = standardized error

*** $p<.001$.

The connection between life events and menopausal symptoms is supported in this research which shows that (independently from socio-demographic, menopausal and health-related variables and lifestyle) life events significantly predicted all menopausal symptoms, except for the urinary ones. This supports the literature which evidences that life events can be related with the exacerbation of psychological menopausal symptoms $[7,19,20]$ and goes further demonstrating that some physical symptoms might be significantly predicted by life events. Hence, women who evaluated their recent life events in a more positive way manifested less severe menopausal symptoms. This conclusion is a pertinent contribution which supports a shift from the medical model of disability to a more social model, concerning the conceptualization of several symptoms frequently regarded as menopausal.

It has been observed that, in the occidental societies, the depreciation of aging, as opposed to youth, strength and extended ability to implement actions, led to the medicalization of age progression as if it was a disease [38]. Menopause, specifically, has been mentioned as a paradigmatic case of medicalization [39]. It was defined as a deficiency disease at a time when synthetic estrogens started being commercialized, and hormonal therapy appeared as a way to delay aging and preserve valuable attributes, such as youth and beauty [40]. It has been suggested that medicalization disables personal-care, leads to the decline of the ability to cope (supported by the cultural context) and promotes a dependence on health services and professionals for one's health management [41]. The promotion and use of hormone therapy, seen in the last decades, has been regarded by the sociological literature as a strong sign of menopause's representation as a medical condition [42].

In this context, the present research allows raising the hypothesis that the perceived severity of many of the symptoms, broadly identified as menopausal (of both physical and psychological nature), are not solely attributed to the change of the menopausal status (in fact, only three were predicted by the changes in menopausal status), but were associated with how women perceived their life events (in terms of negative impact). In addition, several menopausal symptoms can also be predicted by personal variables (for instance, the self-reported health status), not related with menopause.

Consequently, this research emphasises that, on one hand, it is important to consider environmental and individual variables (not necessarily associated with menopause, but important in the context of women's current life), when assessing menopausal symptoms, since these can account for the reported severity of several physical and psychological symptoms. On the other hand, the data supports that, although the literature has evidenced that 
menopausal transition and menopause are linked to the emergence of an array of different symptoms, in this community sample only three symptoms were predicted by menopausal status: skin/facial hair changes, sexual and vasomotor symptoms. As a result, it is hypothesized that these symptoms are the only ones directly subsequent to the menopausal status' changes.

These outcomes emphasize the need to widen the way clinicians and researchers perceive menopause and its related clinical manifestations, since they can be associated with other variables not directly related with menopause, this including the menopausal status.

The sample size used for the structural equation modeling (namely, 710 participants) was adequate for this type of statistical analysis given it was applied a rule of thumb of ten subjects per manifest variable, as is current practice in structural equation modeling $[22,43]$. Nevertheless, the fact that this research has a cross-sectional design, and uses a sample where a third of the women have a college degree, limits the generalization of these results.

\section{Contributors}

None.

\section{Competing interest}

None.

\section{Funding}

F. Pimenta was funded by a PhD grant from the Portuguese Foundation for Science and Technology (grant SFRH/BD/32359/2006).

\section{Acknowledgments}

We kindly acknowledge the Portuguese Fundação para a Ciência e Tecnologia (FCT), for the grant SFRH/BD/32359/2006. We also thank Raquel Oliveira for proof reading the manuscript.

\section{References}

[1] Woods NF, Mitchell ES. Symptoms during the perimenopause: prevalence, severity, trajectory, and significance in women's lives. American Journal of Medicine 2005;118:14-24.

[2] Binfa L, Castelo-Branco C, Blümel JE, et al. Influence of psycho-social factors on climacteric symptoms. Maturitas 2004;48:425-31.

[3] Blümel JEM, Castelo-Branco C, Cancelo MJ, et al. Relationship between psychological complaints and vasomotor symptoms during climacteric. Maturitas 2004;49:205-10.

[4] Sierra B, Hidalgo LA, Chedraui PA. Measuring climacteric symptoms in an Ecuadorian population with the Greene Climacteric Scale. Maturitas 2005;51:236-45.

[5] Sarrel PM. Psychosexual effects of menopause: role of androgens. American Journal of Obstetrics and Gynecology 1999;180:319-24.

[6] Dennerstein L, Dudley E, Hopper J, Guthrie J, Burger HA. A prospective population-based study of menopausal symptoms. Obstetrics and Gynecology 2000;96:351-8.

[7] Deeks AA. Psychological aspects of menopause management. Best Practice and Research Clinical Endocrinology and Metabolism 2003;17: $17-31$.

[8] Genazzani AR, Schneider HPG, Panay N, Nijland EA. The European menopause survey 2005: women's perceptions on the menopause and postmenopausal hormone therapy. Gynecological Endocrinology 2006;22: 369-75.

[9] Obermeyer CM, Schulein M, Hajji N, Azelmat M. Menopause in Morocco: symptomatology and medical management. Maturitas 2002;41:87-95.

[10] Obermeyer CM, Reynolds RF, Price K, Abraham A. Therapeutic decisions for menopause: results of the DAMES Project in central Massachusetts. Menopause 2004;11:456-65.
[11] Obermeyer CM, Reher D, Alcala LC, Price K. The menopause in Spain: results of the DAMES (Decisions At MEnopause) study. Maturitas 2005;52:190-8.

[12] Pinkerton JV, Zion AS. Vasomotor symptoms in menopause: where we've been and where we're going. Journal of Womens Health 2006;15:135-45.

[13] Munarriz R, Talakoub L, Flaherty E, et al. Androgen replacement therapy with dehydroepiandrosterone for androgen insufficiency and female sexual dysfunction: androgen and questionnaire results. Journal of Sex and Marital Therapy 2002;28:165-73.

[14] Hardy R, Kuh D. Change in psychological and vasomotor symptom reporting during the menopause. Social Science and Medicine 2002;55:1975-88.

[15] Vanwesenbeeck I, Vennix P, van de Wiel H. Menopausal symptoms: associations with menopausal status and psychosocial factors. Journal of Psychosomatic Obstetrics and Gynaecology 2001;22:149-58.

[16] Saranson IG, Johnson JH, Siegel JM. Assessing the impact of life changes: development of the Life Experiences Survey. Journal of Consulting and Clinical Psychology 1978;46:932-46.

[17] Yun KW, Kim SI. The influence of life stress on the severity of depression and somatic symptoms in depressive women. Journal of Korean Neuropsychiatry Association 2010;49:304-11.

[18] Vinokur A, Selzer ML. Desirable versus undesirable life events: their relationship to stress and mental distress. Journal of Personality and Social Psychology 1975;32:329-37.

[19] Deeks AA, McCabe MP. Well-being and menopause: an investigation of purpose in life, self-acceptance and social role in premenopausal, perimenopausal and postmenopausal women. Quality of Life Research 2004;13:389-98.

[20] Kaufert PA, Gilbert P, Tate R. The Manitoba Project: a re-examination of the link between menopause and depression. Maturitas 1992;14:143-55.

[21] Pimenta F, Leal I, Maroco J, Ramos C. Menopause Symptoms' Severity Inventory (MSSI-38): assessing symptoms' frequency and intensity. Climacteric 2012;15:143-52, http://dx.doi.org/10.3109/13697137.2011.590617.

[22] Maroco J. Análise de Equações Estruturais. Pero Pinheiro: Report Number; 2010.

[23] Silva I, Pais-Ribeiro J, Cardoso H, Ramos H. Contributo para a adaptação da life events survey (LES) à população diabética portuguesa. Revista Portuguesa de Saúde Pública 2003;21:49-60.

[24] Soules MR, Sherman S, Parrott E, et al. Stages of reproductive aging workshop. Journal of Women's Health and Gender-Based Medicine 2001;10:843-8.

[25] Weisberg S. Applied linear regression. 2nd ed. New York: John, Wiley \& Son; 1985.

[26] Byrne BM. Structural equation modelling with AMOS: basic concepts, applications and programming. London: LEA; 2001.

[27] Pérez JAM, Garcia FC, Palacios S, Pérez M. Epidemiology of risk factors and symptoms associated with menopause in Spanish women. Maturitas 2009;62:30-6.

[28] Avis NE, Stellato R, Crawford S, Johannes C, Longcope C. Is there an association between menopause status and sexual functioning. Menopause 2000;7:297-309.

[29] Mishra G, Kuh D. Sexual functioning throughout menopause: the perceptions of women in a British cohort. Menopause 2006;13:880-90.

[30] Raine-Fenning NJ, Brincat MP, Muscat-Baron Y. Skin aging and menopause: implications for treatment. American Journal of Clinical Dermatology 2003;4:371-8.

[31] Clement YN, Onakpoya I, Hung SK, Ernst E. Effects of herbal and dietary supplements on cognition in menopause: a systematic review. Maturitas 2011;68:256-63.

[32] Newton KM, Reed SD, LaCroix AZ, Grothaus LC, Ehrlich K, Guiltinan J. Treatment of vasomotor symptoms of menopause with black cohosh, multibotanicals, soy, hormone therapy, or placebo: a randomized trial. Annals of Internal Medicine 2006;145:869-79.

[33] Eden JA. Herbal medicines for menopause: do they work and are they safe? Medical Journal of Australia 2001;174:63-4.

[34] Dennerstein L, Dudley E, Guthrie J. Predictors of declining self-rated health during the transition to menopause. Journal of Psychosomatic Research 2003;54:147-53.

[35] Dubnov G, Brzezinski A, Berry EM. Weight control and the management of obesity after menopause: the role of physical activity. Maturitas 2003;44:89-101.

[36] Alati R, Dunn N, Purdie DM, et al. Moderate alcohol consumption contributes to women's well-being through the menopausal transition. Climacteric 2007;10:491-9.

[37] Mansfield PK, Koch PB, Voda AM. Midlife women's attribution for their sexual response changes. Health Care for Women International 2000;21:543-59.

[38] Paúl C, Fonseca AM. Psicossociologia da saúde. Lisbon: Climepsi; 2001.

[39] Sievert LL, Saliba M, Reher D, et al. The medical management of menopause: a four country comparison of urban care. Maturitas 2008;59:7-21.

[40] McCrea FB. The politics of menopause: the "discovery" of a deficiency disease. Social Problems 1983;31:111-23.

[41] Illich I. Medicalization and primary care. Journal of the Royal College of General Practitioners 1982;32:463-70.

[42] Griffiths F. Women's control and choice regarding HRT. Social Science and Medicine 1999;49:469-81.

[43] Kline RB. Principles and practices of structural equation modelling. 2nd ed. New York: The Guilford Press; 2005. 